\title{
Magnetic nanoparticles are highly toxic to chloroquine-resistant Plasmodium falciparum, dengue virus (DEN-2), and their mosquito vectors
}

\begin{abstract}
A main challenge in parasitology is the development of reliable tools to prevent or treat mosquito-borne diseases. We investigated the toxicity of magnetic nanoparticles (MNP) produced by Magnetospirillum gryphiswaldense (strain MSR-1) on chloroquine-resistant (CQ-r) and sensitive (CQ-s) Plasmodium falciparum, dengue virus (DEN-2), and two of their main vectors, Anopheles stephensi and Aedes aegypti, respectively. MNP were studied by Fourier-transform infrared spectroscopy and transmission electron microscopy. They were toxic to larvae and pupae of An. stephensi, $\mathrm{LC}_{50}$ ranged from $2.563 \mathrm{ppm}$ (1st instar larva) to $6.430 \mathrm{ppm}$ (pupa), and Ae. aegypti, $\mathrm{LC}_{50}$ ranged from $3.231 \mathrm{ppm}$ (1st instar larva) to $7.545 \mathrm{ppm}$ (pupa). MNP IC 50 on P. falciparum were $83.32 \mu \mathrm{g} \mathrm{ml}^{-1}$ (CQ-s) and $87.47 \mu \mathrm{g} \mathrm{ml}^{-}$ ${ }^{1}$ (CQ-r). However, the in vivo efficacy of MNP on Plasmodium berghei was low if compared to CQ-based treatments. Moderate cytotoxicity was detected on Vero cells post-treatment with MNP doses lower than $4 \mu \mathrm{g} \mathrm{ml}^{-1}$. MNP evaluated at 2-8 $\mu \mathrm{g} \mathrm{ml}^{-1}$ inhibited DEN-2 replication inhibiting the expression of the envelope (E) protein. In conclusion, our findings represent the first report about the use of MNP in medical and veterinary entomology, proposing them as suitable materials to develop reliable tools to combat mosquito-borne diseases.
\end{abstract}

Keyword: Antiviral activity; Malaria; Magnetospirillum gryphiswaldense; Magnetotactic bacteria; Yellow fever; Zika virus 